\title{
Numerical analysis of collision forces between Ford truck and high-speed railway bridge piers
}

\author{
Cui Kunpeng ${ }^{1, a}$, Wang Yupeng ${ }^{1, b}$, Xia Chaoyi ${ }^{2, c}$ and Xia He ${ }^{2, d}$ \\ ${ }^{1}$ CCCC Road and Bridge Consultants CO., LTD., Beijing 100011, China \\ 2 School of Civil Engineering, Beijing Jiaotong University, Beijing 100044, China \\ acuikunpeng2004@163.com, b895842457@qq.com, cxiacy88@163.com, dhxia88@163.com
}

\begin{abstract}
Keywords: high-speed railway; bridge pier; vehicle collision; numerical simulation
Abstract. For high-speed railways with elevated bridges, the probability of vehicle colliding with piers becomes high. A Ford truck and railway pier system is established to analyze the collision force characteristics by using finite element soft ANSYS LS_DYNA. Four different truck speeds, $60 \mathrm{~km} / \mathrm{h}$, $80 \mathrm{~km} / \mathrm{h}, 100 \mathrm{~km} / \mathrm{h}$ and $120 \mathrm{~km} / \mathrm{h}$ are simulated to extract the collision force-time histories and analyze the force characteristics. The result shows that this method is feasible to simulate an vehicle collision with pier and to gain impact force time histories, the collision energy mainly concentrates on the low frequency, and the higher the impact speed, the more component of high-frequency. The simulated dynamic truck collision force is much greater than the design value in the Chinese railway code, so it is necessary to consider this problem.
\end{abstract}

\section{Introduction}

With the development of high-speed railways in China, more and more elevated bridges are constructed. For example, on the Beijing-Shanghai high-speed railway of 1318 kilometers, the bridge length accounts for $80.5 \%$ of the total. When a bridge crosses a river, its piers in the river may be collided by vessels or other floating objects. For a railway bridge that steps across another roadway, its piers close to the road may be collided by moving vehicles. Although these accidents are rare, once happened, they would cause serious damage to life, property, society and environment ${ }^{[1-3]}$.

When a collision load acts on bridge pier, it may cause dislocation of bearings and beams, uneven deformation or fracture of expansion joints, and even beam collapse. For high-speed railway bridges, however, even if there is no beam collapse, the vibration and displacement induced by collision may deform the track and make it instable, which may further threaten the running safety of train vehicles. During the collision, the vehicle on the bridge may derail from the track in case that the collision is intense and the train's running speed is high ${ }^{[4-5]}$.

In the Code for Design of High-speed Railways (TB10621-2009) issued by the Ministry of Railways in China, it is stipulated that a collision force should be considered in bridge pier design, which is represented by an $1,000-\mathrm{kN}$ static force if they are not protected by a crashworthy barrier. The force is applied to the pier horizontally at $1.20 \mathrm{~m}$ above the ground, while it is unclear about the origins of the provision and it does not explain that basis of the design forces. This paper discusses this issue and presents the results of detailed finite element analysis of vehicle/pier collision, to evaluate the process of vehicle collision with pier.

\section{Analysis Model}

To simulate the vehicle collision process more accurately, the finite element models for vehicles issued by the National Crash Analysis Center (NCAC, America) ${ }^{[6]}$ is adopted. The models are established and digitized from the geometry information of each part of the vehicles, based on a large number of automobile tests and engineering experience. These models have received the recognition and development from the federal government for vehicle collision research center, therefore, using these models to simulate the truck has a high credibility. More detail information about the vehicle models and the simulation procedures can be downloaded from the NCAC's website. 
Select a Ford truck with a weight of $8.0 \mathrm{t}$ as an example to represent the medium weight trucks, as shown in Fig. 1. The FE model of the selected truck includes 21400 elements and 38949 nodes. Different material models are adopted to simulate different parts of the truck. Elastic material model is adopted for the engine, transmission and radiator, while a rubber material for the tires. As for the chassis, the front shell, the compartment and some other parts of the structure with inelastic property, an isotropic elastic-plastic material model is adopted. Different types of elements, such as shell, solid and beam elements are introduced corresponding to various components of the structure. By connecting the various parts with rigid constraints, a whole model is obtained reflecting the true condition of the vehicles. More details can be found on the website of NCAC and Reference [6].



Fig. 1. FE model of Ford truck.

A round-end pier in actual service is selected, which can be referenced from the bridge design code for double line high-speed railway line on speed of $350 \mathrm{~km} / \mathrm{h}$. The pier uses C30 reinforced concrete, with the cross section of $760 \mathrm{~cm} \times 300 \mathrm{~cm}$, the height of $710 \mathrm{~cm}$. Detailed geometric dimensions can be seen in Fig. 2.
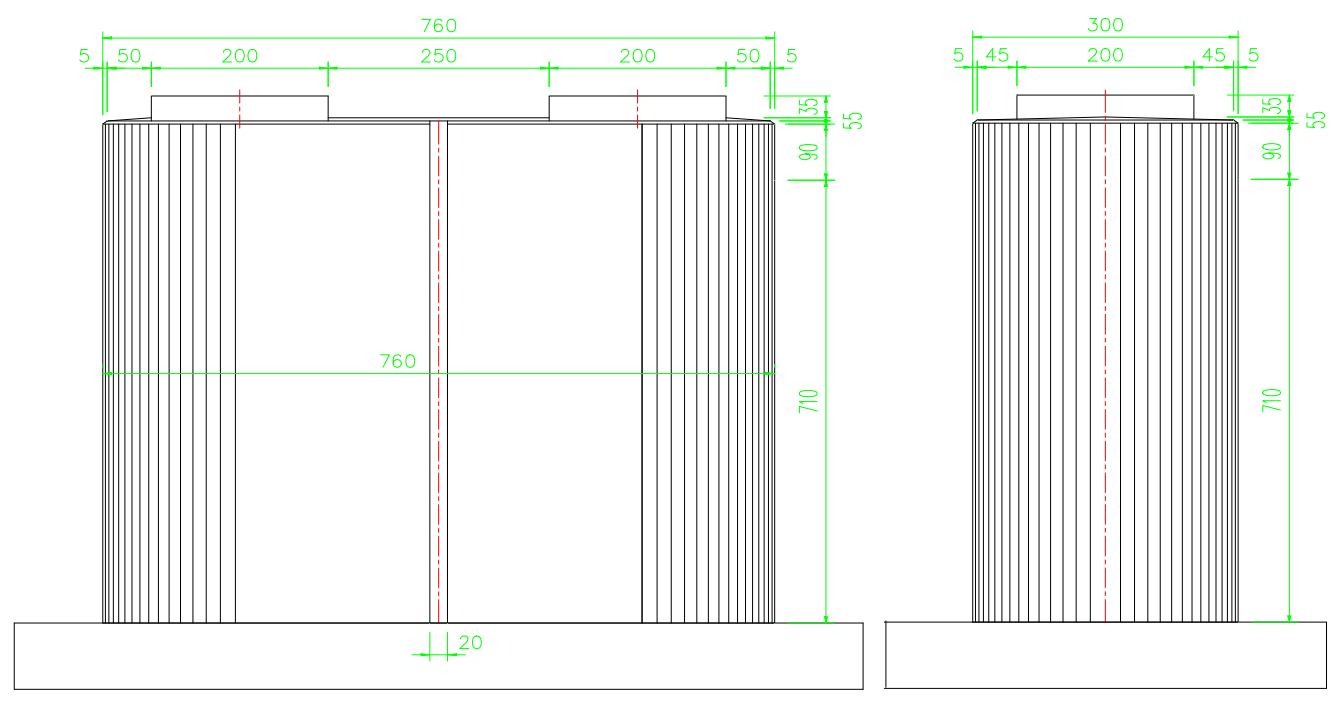

Fig. 2. Geometric dimensions of the pier.

The finite element model adopts Solid 164 unit and Brittle_damage ${ }^{[3,7]}$ models. The constitutive of the Brittle_damage model is based on damage mechanics theory, which can simulate well the tensile fracture behavior of concrete.

\section{Parametric Study and Result Analysis}

The limit speed for roadway and highway in China are respectively $60 \mathrm{~km} / \mathrm{h}$ and $120 \mathrm{~km} / \mathrm{h}$, so four speeds, $60 \mathrm{~km} / \mathrm{h}, 80 \mathrm{~km} / \mathrm{h}, 100 \mathrm{~km} / \mathrm{h}$ and $120 \mathrm{~km} / \mathrm{h}$, are select for the truck. The setting calculated time is $0.6 \mathrm{~s}$, with the output of 120 steps. 
Since the size and the weight of the pier are very big, in a case of a light truck collision, especially with low speed, the destruction of the pier is usually unobvious. The collision time history data are extracted from this simulation course, and the process and the corresponding laws of vehicle collision with bridge pier are analyzed.

In the Ls_PrePost software, it is convenient to see the whole simulated impact process of the Ford truck in four different speeds. Clearly shown in Figs. 3 5 are the deformation courses of the truck hitting on the pier at $120 \mathrm{~km} / \mathrm{h}$ speed.
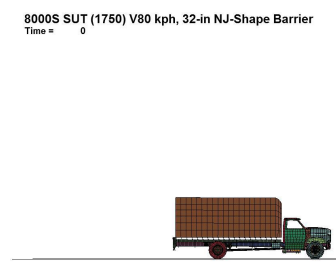

Ex

Fig. 3. Before collision.
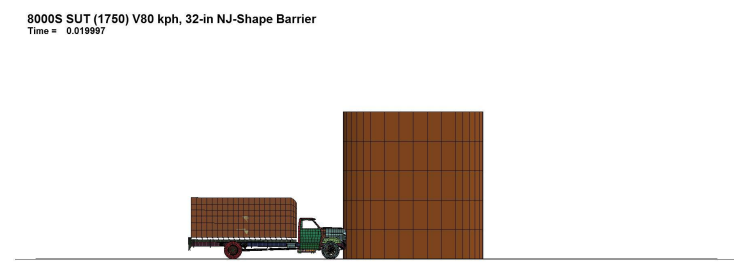

$z_{x}$

Fig. 4. Collision begins.

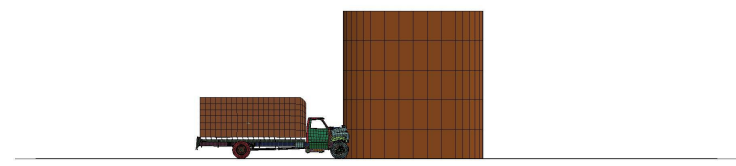

Ex

Fig. 5. Peak force appears at $0.0350 \mathrm{~s}$.

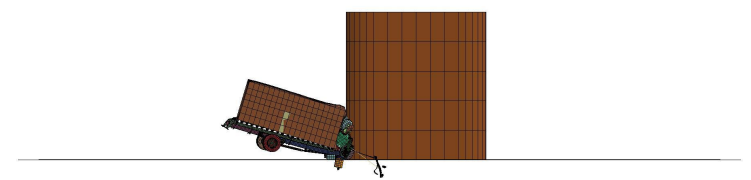

$x^{2}$

Illustrated in Fig. 7 are the time history curves of the collision forces of the Ford truck with the pier at four different speeds.

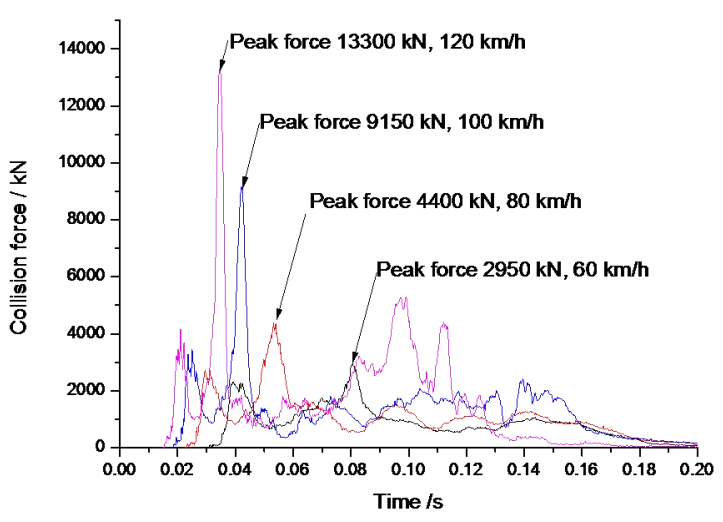

Fig. 7. Force-time histories of collision forces of the Ford truck at different speeds

It can be seen from the figure that the collision duration is less than $0.20 \mathrm{~s}$, and the curves show the narrow pulse load form with only about $0.01 \sim 0.02 \mathrm{~s}$ in width. The intensity (maximum value) of the collision force increases with the truck speed approximately in linear relationship. The peak collision forces are $2950 \mathrm{kN}, 4400 \mathrm{kN}, 9150 \mathrm{kN}$ and $13300 \mathrm{kN}$, respectively, corresponding to the truck speeds of $60 \mathrm{~km} / \mathrm{h}, 80 \mathrm{~km} / \mathrm{h}, 100 \mathrm{~km} / \mathrm{h}$ and $120 \mathrm{~km} / \mathrm{h}$. The higher the collision speed is, the earlier the peak value appears and the narrower the pulse width is. There are several peaks appearing in the curves, with each indicating some part of the truck participated and damaged in the collision. 
The frequency spectrum analysis is applied to the collision force time histories using the Fast Fourier Transform (FFT), and the spectral density curves corresponding to four truck speeds are shown in Fig. 8.



Fig. 8. Spectrum density curves of collision force of the truck at different speed.

From the figure one can observe that the main impact energy concentrates in $20 \mathrm{~Hz}$. Within the frequency band less than $10 \mathrm{~Hz}$, the spectral density values are high, normally more than $400 \mathrm{kN} / \mathrm{Hz}$, with the maximum value close to $1350 \mathrm{kN} / \mathrm{Hz}$ appearing at $0 \mathrm{~Hz}$. The spectral densities of $60 \mathrm{~km} / \mathrm{h}$ and $80 \mathrm{~km} / \mathrm{h}$ are closed to zero at $110 \mathrm{~Hz}$, that of $100 \mathrm{~km} / \mathrm{h}$ and $120 \mathrm{~km} / \mathrm{h}$ close to zero in $250 \mathrm{~Hz}$, showing that the higher the truck speed is, the more component the high frequency contains.

Equivalent static force means the static force value to produce the same displacement corresponding to the dynamic load at the same applied point, which depends on the stiffness and dynamic characteristics of the system ${ }^{[8]}$.

Shown in Fig. 9 is the comparison among the peak collision force, equivalent static force and the limited static force given by the Code for Design of High-speed Railways (TB10621-2009) issued by the Ministry of Railways in China. One can see that when the truck speed exceeds $60 \mathrm{~km} / \mathrm{h}$, all the equivalent static forces are highly beyond the code limit of $1000 \mathrm{kN}$, and the peak collision force goes up to more than ten thousands of $\mathrm{kN}$. All that above indicate that the collision force given in the code is insufficient for design of bridge piers. Therefore, it is necessary to consider the dynamic response of vehicle collision with pier to ensure the safe operation of the high-speed trains.

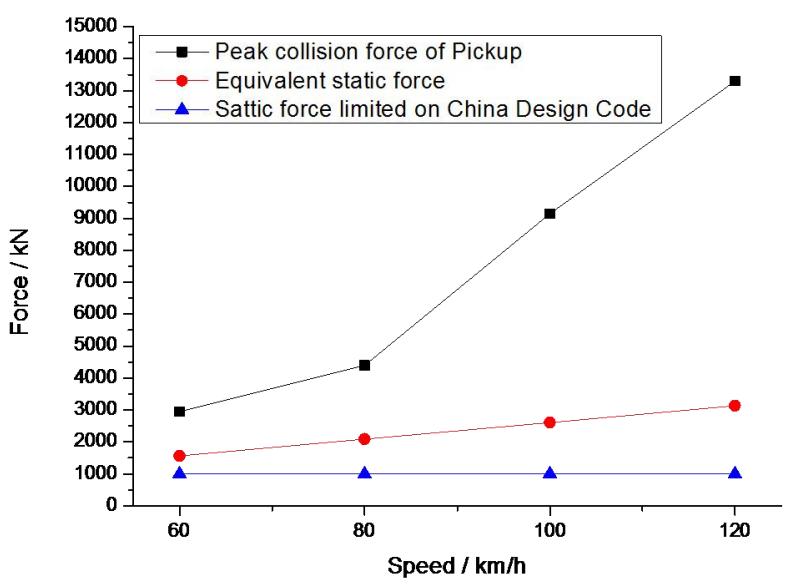

Fig.9 Comparison of collision force values. 


\section{Conclusions}

This paper established a truck and pier simulation system by finite element software ANSYS LS_DYNA to analyze the collision force characteristics. The force-time histories and the spectrum densities of the truck colliding on the pier at different velocities are gained. The following conclusions can be drawn from the analysis:

(1) The higher speed is, the earlier the peak collision force appears, and the narrower the pulse width is.

(2) The collision force duration is short, less than $0.2 \mathrm{~s}$.

(3) The equivalent static forces greatly exceed the limited static force in the China High-speed Railway Code, and the peak force can reach more than ten thousands of $\mathrm{kN}$, so it is necessary to consider the dynamic response in railway bridge pier design.

(4) The spectrum density analysis shows that the collision energy concentrates in $20 \mathrm{~Hz}$. Within the frequency band less than $10 \mathrm{~Hz}$, the spectral density values are high, normally more than 400 $\mathrm{kN} / \mathrm{Hz}$, with the maximum value close to $1350 \mathrm{kN} / \mathrm{Hz}$ appearing at $0 \mathrm{~Hz}$.

This method is feasible to simulate a vehicle collision with pier and gain an impact force time history as an input excitation for a further study in the high-speed train and bridge coupling system.

The collision analysis of vehicle-pier system is a rather complex problem, which is related with the speed and the mass of the vehicle, the form and size of the pier, the impact angle, the acting position, and so on. In this paper, only a preliminary study is performed, and there need a further theoretical and experimental research.

\section{Acknowledgements}

This paper is supported by the Major State Basic Research Development Program of China (973 Program: 2013CB036203).

\section{References}

[1] Xia Chaoyi, Dynamic responses of train-bridge system subjected to collision loads and running safety evaluation of high-speed trains. Beijing: Beijing JiaoTong University. (in Chinese)

[2] Wang Junjie. Research and engineering applications on ship collision with bridge. Beijing: People's Communications Press, 2011. (in Chinese)

[3] Lu Xinzheng, He Shuitao, Huang Shengnan. Research on collision between over-height vehicles and bridge superstructure. Beijing: China Building Industry Press, 2011. (in Chinese)

[4] C.Y. Xia, J.Q. Lei, N. Zhang, et al. Dynamic analysis of a coupled high-speed train and bridge system subjected to collision load. Journal of Sound and Vibration. 2012, 331(10): 2334-2347.

[5] Xia He, Zhang Nan. Dynamic Interaction of Vehicles and Structures. Science Press, Beijing. 2005.

[6] Sherif EI-Tawil P.E.M., ASCE, et al. Vehicle collision with piers. Journal of Bridge Engineering, 2005, 10(3): 344-353.

[7] Xu, L.J., Lu, X.Z., Smith, S.T., et al. Scaled model test for collision between over-height truck and bridge superstructure. International of Impact Engineering. 2012, 49: 31-42.

[8] Yu Min, Cha Xiaoxing. Research on performance of the motor collision with real hollow concrete column. Progress in Steel Building structures. 2011, 13(1): 57-64. (in Chinese) 